\title{
The Effect of Educational Intervention on Promotion of Preventive Behavior of Knee Osteoarthritis in Women Over 40 Based on the Theory of Planned Behavior in Sample of Iranian Women
}

\author{
Ali Khani Jeihooni \\ Shiraz University of Medical Sciences \\ Zhila Fereidouni \\ Fasa University of Medical Science \\ Mina Bahmandoost \\ Fasa University of Medical Science \\ Pooyan Afzali Harsini ( $\sim$ pooyanafzali@gmail.com ) \\ Kermanshah University of Medical Sciences https://orcid.org/0000-0003-1689-6895
}

Research article

Keywords: Knee osteoarthritis, Women, Theory Planned Behavior, educational intervention

Posted Date: July 7th, 2021

DOl: https://doi.org/10.21203/rs.3.rs-656824/v1

License: (9) (i) This work is licensed under a Creative Commons Attribution 4.0 International License.

Read Full License 


\section{Abstract}

Objectives. The purpose of this study was designed and conducted so that the educational intervention based on the theory of planned behavior be performed in order to promote preventive behaviors of knee osteoarthritis in women over 40 living in, Fars, I.R.Iran

Methods. This research is a quasi-experimental study. The subjects of the study were 100 women over the age of 40 who were under the coverage of Health Centers. The data collection tool was a questionnaire TPB. The educational intervention program consisted of 8 training sessions on the adoption of preventive behaviors from knee osteoarthritis based on the theory of planned behavior (TPB).

Results. There was a significant difference between the experimental and control groups in terms of the scores for attitude, subjective norms, perceived control behavior, intention and behavior before and after the intervention. However, three months after the intervention, there was a significant increase in each of the constructs in the experimental, but there was no such a significant difference in the control group.

Conclusion. With regard to the findings of this study, performing educational intervention based on theories and changing behavior modes particularly the TPB aiming at reducing knee osteoarthritis can lead to its morbidity reduction.

\section{Background}

Degenerative Joint Diseases (DJD) are of the most common rheumatic diseases in humans across the world. The studies show that more than $40 \%$ of adults over the age of 70 have knee osteoarthritis (1). These debilitating diseases are associated with a decreased quality of life, and now with increasing life expectancy, we can expect the prevalence of these diseases to rise (2). Osteoarthritis is the commonest type of arthritis and joint disease in humans (3). Cartilage wearing down or knee arthritis is amongst the commonest degenerative disorders of the musculoskeletal system especially in the elderly leading to physical disability and dependency in the patients (4\&5). Osteoarthritis is a degenerative joint disease in nature, which is referred to as progressive joint disease (6). Osteoarthritis is a slowly progressive disease (7). It is more common among elderly and women (8). It is estimated that in adults, the most common knee joint is osteoarthritis ( $41 \%$ compared to $30 \%$ arthritis in the hands and $19 \%$ arthritis in the hips) (9). Due to pain and loss of mobility, the quadriceps muscle of people with osteoarthritis is subject to atrophy and weakness (10). As osteoarthritis progresses, it results in wearing down of the cartilage, bone and surrounding soft tissue (ligaments, capsule, tendon and muscle), and eventually causes deformity of knee, laxity or ligament instability (10). The knee joint is considered to be the biggest joint in terms of volume and articular surface; therefore, it is easily injured, and torn and exposed to tendon damage and inflammatory arthritis (11). Knee pain is very common and causes a large percentage of patients to refer to doctors (12). Arthritis is amongst the prevalent diseases in both developed and developing countries (13), including Iran (14). Based on the studies carried out in Iran, the prevalence of arthritis in urban and 
rural areas is $16.6 \%$ and $15.5 \%$ respectively (11). The prevalence of osteoarthritis of the knee was shown to be $15.3 \%$ among people over the age of 15 (14). In a study conducted in Iran in 2009, the way people sit was reported to be cross-legged and kneeling while climbing stairs and carrying a load did not increase the risk of developing the disease (4). Overall, 9 out of 10 referred patients over the age of 30-35 complaining of knee, back and neck pain, are those suffering from osteoarthritis (3). At present, the prevalence of the disease is on the rise and it is expected that this trend will continue with increasing life expectancy and the prevalence of obesity (15).

The knee Joint consists of 3 articulatory bones: the shin bone (tibia), the thigh bone (femur), and the kneecap (patella). The articular cartilage, the slippery substance, helps the bones of the knee to glide smoothly across each other and have an essential role in performing daily activities as one can bend or straighten his/her legs. In addition to these three bones, four other important tissues are involved in the structure of the knee joint which are as follows: 1. Meniscus, 2. Ligaments, 3. synovium (synovial membrane) 4. Articular capsule, (hard, fibrous connective tissue surrounding articular surfaces of the three above-mentioned bones, meniscus, ligaments, synovium). Any disease or injury to each of the above-mentioned tissues, comprising the structure of the knee joint, causes pain and knee problems. Lots of knee pain cases are induced by lesions and the problems of knee elements and its surrounding tissues which should be diagnostically differentiated from the internal causes of knee joint pain (16). Osteoarthritis is divided into two types: primary and secondary. Primary osteoarthritis in which the process of cartilage degeneration and destruction occurs without any previous underlying background has no specified cause. It tends to develop in people over the age of 40 in a slow progression and in several joints which is caused by normal or abnormal repetitive stress on the weakened joints leading to joint pain and swelling. Secondary osteoarthritis follows a previous disease and underlying bone injuries. Conditions that lead to secondary osteoarthritis include fractures, arthritis, infections, rheumatoid arthritis, tumors, congenital abnormalities and metabolic diseases (3). Except for cartilage tissue having no blood vessels and nerves, any damage or injury to each of four tissues comprising the knee joint causes knee pain. Loss of cartilage alone does not directly cause a pain, but as the degenerated tissue is replaced by ossification and tiny crevasses of cartilage are released in the joint space, the synovial membrane is stimulated, thereby it both causes the pain and increases the water content of the cartilage giving rise to swelling and the pain in the knee joint. In an adult, the normal volume of knee joint fluid is up to $2 \mathrm{ml}$; however, it may reach up to 150 to $200 \mathrm{cc}$ in abnormal conditions. Increased water content of the cartilage and the swelling in the knee by itself is not a disease, but like a pain, it is considered to be a symptom of a disease (12). The most common cause of chronic knee pain is impacts_stresses or chronic strain. In general, knee pain can be treated by taking care of the knee and keeping it relatively motionless for 3 weeks to 3 months. The most reliable guide in the treatment course is the symptom of pain. The knee must be in a position or be at an angle in the range of motion so that it can serve its function causing no pain and without taking any medication. If the state of not feeling pain in the knee lasts (in different cases, it ranges from 3 weeks to 3 months), the knee pain will be relieved. If the knee pain is not relieved through this method, it is necessary to take diagnostic and professional treatment measures (17). At present, osteoarthritis is the fourth leading cause of 'years lived with disability' 
(accounting for approximately $3 \%$ of total YLDs) (18). Osteoarthritis is a major cause of malfunction and has a great impact on people's lives, including mobility, independence and daily activities leading to limited recreational, sports and occupational activities. The knee joint is the commonest site of musculoskeletal pain in Iran (3). Osteoarthritis seems to be caused by such known risk factors as obesity, age, female gender, weight, body mass index (BMI), post menopause, genovarum, incorrect habits (carrying heavy loads repeatedly, cross-legged sitting or sitting in kneeling position, Iranian (squatting)toilet habit of emptying the bowels) ; however, level of education is considered as a protective factor (14). The researchers' evidence and experience are indicative of patients' frequent referral to doctors and imposing heavy costs on their families (19) which, as a public health issue, is of great importance as the communities get older (11). Preventive interventions play a significant role on the reduction and progression of the disease because it not only has an impact on the patients' lifestyle but it also reduces the associated economic burden imposed on the families and community. The preventive approaches should focus on modifiable risk factors. Arthritis is also more common in women than men (1). Yoshimura study (20) showed that women were more affected by knee osteoarthritis than men. In the study by Zeng (21), it was claimed that 'the prevalence of knee osteoarthritis was significantly higher in women than in men with a tendency of increase with age. The prevalence was increased more obviously in women after 40 years old and in men after 45 years old'. Health experts believe that a core component of the management of osteoarthritis is lifestyle modification -i.e., making a change in wrong behaviors and following healthy behaviors in the long run (22). Osteoarthritis can be prevented and its severity and associated symptoms can be decreased through making lifestyle changes, treating genu varum deformity before the advent of arthritis and reducing weight in obese patients (1). Therefore, the prevalence rate of osteoarthritis, its complications and due challenges can be reduced by adopting an appropriate and healthy lifestyle (23). The best strategy for reducing the burden of the disease is preventive interventions (primary and secondary) because it reduces the economic burden on society and the family (24). To achieve the educational goals and to implement educational programs in order to improve the program, it is important to choose an appropriate health model (25). Using the most appropriate theory significantly increases the chances of effective health education works and health promotion and it will help the program designers correctly understand the factors affecting environmental and health behaviors and select an appropriate target group for interventions, development of strategies and educational materials so that the interventions become more successful and more economical in terms of time and cost-effectiveness (26). One of the theories used to predict the behavior is the theory of planned behavior (TPB) which predicts an individual's intention to engage in a behavior at a specific time and place. According to this theory, the most important component of a human action is their intention which is guided by behavioral beliefs, normative beliefs, and control beliefs (27). The advantage of measuring the intention of behavior is that should it not be measurable in the form of an intervention, it can be used a helpful index (28). With respect the importance of prevention of osteoarthritis in vulnerable people, especially women, this study was designed and conducted so that the educational interventions based on the theory of planned behavior be performed in order to promote preventive behaviors of knee osteoarthritis in women over 40 living in, Fars, I.R.Iran. 


\section{Materials And Methodology}

This research is a quasi-experimental study. The subjects of the study were 100 women over the age of 40 who were under the coverage of Health Centers. Two out of six Health Centers were randomly selected (one center for the control group and the other for experimental group). In each Health Center, 50 subjects were selected based on the number of their family files recorded in the Health Centers (50 patients in the experimental group and 50 in the control group). Setting Type I error as $5 \%$ (the level of significance) and the power of experiment as $95 \%$ and reaching to a mean difference of $20 \%$, the sample size was selected to be 100 participants. The inclusion criteria were: a) women over 40 , and b) literacy. The exclusion criterion was women with knee arthritis. However, taking part in the study was voluntary and the volunteers were informed of the confidentiality of the data. Having been selected as the experimental and control groups, the two groups completed the questionnaires. Afterwards, the intervention began in the experimental group. The educational intervention program consisted of 8 training sessions on the adoption of preventive behaviors from knee osteoarthritis based on the theory of planned behavior (TPB). Presenting lectures, group discussions, role playing and showing videos and PowerPoint presentations formed the educational intervention program. Workshops were also held by orthopedist and physiotherapists in two of the training sessions, one of which a member of the subject's family attended. At the end of training sessions, the experimental group was given the instructional booklet. In addition, two monthly follow-up sessions were held for the participants and a text message was sent to the women every week. Three months after the intervention, both the experimental and control groups completed the questionnaires.

The data collection tool was a questionnaire consisting of two parts: the first part included 4 questions related to the subjects' background information on age, education level, marital status and BMI.

The second part included items which measured TPB constructs e.g., behavioral beliefs, normative beliefs, control beliefs, intention and behavior. The researchers designed a TPB questionnaire on Ajzen's recommendations (1991) serving as a basis for building each construct used in the research tool (28). The researchers used other studies (29) as well. The data were collected through a self-reported questionnaire eliciting responses from the participants. The content validity of the questionnaire items was approved by health education professionals and rheumatologists. The reliability of the questionnaires was confirmed by carrying a pilot study out and using Cronbach's Alpha. Cronbach's alpha estimations for constructs under study were in the range of 0.70 to 0.89 indicating acceptable internal consistency. The subjects' awareness was tested through 12 multiple choice items; any correct answer was given 1 score and zero for the wrong choice. Twelve question items measuring the subjects' attitude were designed based on standard 5-point Likert scale from 1 (completely disagree) to 5 (completely agree). In order to measure subjective norms, the researchers used 11 items, e.g. 'To prevent knee osteoarthritis, my friends believe that I should have a proper weight', or 'To prevent knee osteoarthritis, my family rarely use ladders'. This construct was also measured based on standard 5-point Likert scale from 1 (completely disagree) to 5 (completely agree). Ten items were used to measure perceived behavioral control. An example of the items was: 'Due to time constraints, it is impossible for me to take exercise'. 
These items were also measured based on 5-point Likert scale from 1 (completely disagree) to 5 (completely agree). The subjects' intention of behavior was measured through 9 items. For instance: 'I have intended to do regular exercise in order to prevent osteoarthritis'. The questionnaire for measuring behavior contained 9 items based on rating scale from 1 (not at all) to 5 (always). The scores for all constructs were calculated in terms of percentage. The collected data were analyzed by using SPSS (Statistical Package for Social Sciences) version 22. In order to analyze the data, the researchers used descriptive statistics (mean and standard deviation), independent T-test, chi-square, and t-pair test. The significance level was set at $.05 \%$.

\section{Findings}

The findings showed that the mean age of women in the experimental group was $51.22 \pm 12.35$, and in the control group was $50.39 \pm 12.64$. The mean of BMI in the women of the experimental and the control group was $22.54 \pm 3.34$ and $23.01 \pm 3.21$ respectively; however, the independent $t$-test showed no significant difference between the two groups. The Chi-square test showed that there was no statistically significant difference between the two groups in terms of education level $(P=0.34)$ and marital status ( $P$ $=0.28$ ). Table 1 shows the demographic data of the women.

The T-test showed that there was a significant difference between the experimental and control groups in terms of the scores for attitude, subjective norms, perceived control behavior, intention and behavior before and after the intervention. However, three months after the intervention, the t-pair test showed that there was a significant increase in each of the constructs, but there was no such a significant difference in the control group (See table 2).

\section{Discussion}

Educational interventions play a significant role in promoting preventive behaviors because they not only affect the quality of individuals' life but also they reduce the economic burden imposed on the family and the community rooted in this disorder. The education of community to observe safety principles and to avoid risky activities can sometimes prevent knee osteoarthritis. With the aim of applying the theory of planned behavior (TPB), the researchers made an attempt to promote preventive behaviors from knee osteoarthritis in women over 40 in, Fars, I.R.Iran. The results of the present study showed that the mean score for women's attitude toward preventive behaviors from knee osteoarthritis significantly increased in the experimental group after performing educational intervention. The use of group discussion and roleplaying led the subjects to have a tendency to take preventive behavior measures from knee osteoarthritis following a model process. To strengthen the subjects' attitudes, they were given a training booklet at the end of the training program and they were sent motivational messages every week. In a study by Mohammadi Zaidi et.al., which was carried out on 150 computer users, it was shown that there was a significant increase in the mean score of the subjects' attitudes in the experimental group compared to that of control group (30). However, the study by Mazlumi et al. showed that educational intervention had no effect on the subjects' attitudes (29). Consistent with the results of this study are 
Reddy et al. (31) and Kwan et al. studies (32) showing that there was a significant increase in the mean score of the subjects' attitude after educational intervention. Compared to the subjects in the control group, the mean score for the subjects' subjective norms in the experimental group was significantly increased after the intervention. In this study, two teaching sessions were held for subjects by orthopedist and physiotherapist considered as influential people. In addition, a teaching session was held which the members of the subjects' family as abstract influential subjective norms in applying preventive behaviors from knee osteoarthritis. Families can help members use preventive behaviors by providing them with suitable conditions and all-through supports. In some studies, educational intervention based on the theory of planned behavior resulted in a significant increase in the mean score of subjective norms in the experimental group $(33,34,35)$. But the studies done by Mazlumi et al. (29) and Mohammadi Zaidi et al. (30), showed that the educational interventions based on the theory of planned behavior (TPB) had no effect on the mean score of subjects' subjective norms as the study by Mehri et al. did, too (36). In this study, there was a significant increase in the mean score for perceived behavior control in the intervention group than the control group. Teaching cognitive skills and new behavior through training sessions and providing the subjects with appropriate feedback and information in group discussions gave rise to the betterment of behavior control in the experimental group. Robertson et al. showed that teaching of ergonomics in the working places and offices could significantly improve perceived control and body posture (37). In the study by Mohammadi Zaidi, the experimental group could get a higher score for perceived behavior control 3 and 6 months after the educational intervention than the control group (30). Mazlumi et al. study showed that the subjects' score for perceived behavior control was higher than that of the control group (29). The study by Martin emphasized the positive role of perceived behavior control in adopting appropriate behavior (38). The results related to women's intention regarding preventive behaviors from knee osteoarthritis showed that the mean score for behavior intention significantly increased in the intervention group compared to that of the control group. Following the theory of planned behavior (TPB), increased mean score of attitude, subjective norms, and perceived behavior control in the experimental group 3 months after the educational intervention led to promotion of intention behavior which reflects the positive effect of educational intervention. In Mohammadi Zaidi et al. study (30), educational intervention resulted in promotion of individuals' intention to improve their physical conditions 3 and 6 months after the intervention. In the studies by Monsali et al. (39) and Allahverdipour et al. (40), educational intervention based on theory of planned behavior (TPB) increases the intention of the subjects. The findings of this study showed that educational intervention based on theory of planned behavior (TPB) resulted in the promotion of preventive behaviors from knee osteoarthritis in women over 40 in the experimental group. The theory-based educational intervention focusing on factors affecting promoting of preventive behavior by using group discussion and active participation of women, clarifying the benefits, the barriers and consequences of the adoption of preventive behaviors, applying approaches to enhance skills and improve communication skills, decision making, problem solving and learning appropriate behavior along with providing appropriate feedback could improve preventive behaviors from knee osteoarthritis in the experimental group. Kalte et al. study showed that educational intervention on ergonomics is effective in reducing musculoskeletal damaging factors (41). Viljanen et al. found out that the impact of educational programs on the reduction of work-related ergonomic problems was significant 
(42). Thomas et al. in their study carried out on 786 men and women 45 years and more showed that presented educational program gave rise to the reduced knee pain in the subjects (43). The studies by Albaladejo (44), Coleman (45), French (46), Kroon (47), Tavafian (48) all emphasized the role of educational intervention on the betterment of the subjects' performance. In the studies conducted by Erfanian and Zorofi, a significant improvement was seen in both experimental and control groups by making some resistance changes in the pain variables (49). The study by Allegrante et al. showed that a training walking program resulted in the performance improvement of the patients with knee osteoarthritis (50). In the study done by Mazlumi et al., it was shown that educational intervention based on the theory of planned behavior (TPB) led to a significant increase in the subjects' score for behavior in the experimental group, but not in the control group (29). With regard to the findings of this study, performing educational intervention based on theories and changing behavior modes particularly the theory of planned behavior (TPB) aiming at reducing knee osteoarthritis can lead to its morbidity reduction. Educational interventions should be tailored through mastering learning skills and alternatives so that they could make the target group accept the desired changes. Lack of organizational and financial support as well as self-reported data collection approach are among such limitations the researchers encountered during implementation of preventive programs.

\section{Conclusion}

Osteoarthritis can be prevented and its severity and associated symptoms can be decreased through making lifestyle changes, treating genu varum deformity before the advent of arthritis and reducing weight in patients. Educational intervention based on theories and changing behavior modes particularly the TPB, aiming at reducing knee osteoarthritis can lead to its morbidity reduction. In this study, three months after the intervention, there was a significant increase in the score of attitude, subjective norms, perceived control behavior, intention and behavior in the experimental, but there was no such a significant difference in the control group.

\section{Abbreviations}

TPB: Application of Theory Planned Behavior

DJD: Degenerative Joint Diseases

\section{Declarations}

Ethics approval and consent to participate:

Research and Technology of Fasa University of Medical Sciences

Consent for publication:

Not applicable 
Availability of data and materials:

Not applicable

Competing interests:

authors declare no conflict of interest

Funding:

Fasa University of Medical Sciences

Authors' contributions:

designing the study: Ali Khani Jeihooni ${ }^{1}$, Zhila Fereidouni ${ }^{2}$, Mina Bahmandoost ${ }^{3}$, Pooyan Afzali Harsini $4^{*}$

carrying it out: Ali Khani Jeihooni ${ }^{1}$, Zhila Fereidouni ${ }^{2}$, Mina Bahmandoost ${ }^{3}$, Pooyan Afzali Harsini ${ }^{4 *}$ analysing the data: Ali Khani Jeihooni ${ }^{1}$, Zhila Fereidouni ${ }^{2}$, Mina Bahmandoost ${ }^{3}$, Pooyan Afzali Harsini ${ }^{4}$ writing the article: Ali Khani Jeihooni ${ }^{1}$, Zhila Fereidouni ${ }^{2}$, Mina Bahmandoost ${ }^{3}$, Pooyan Afzali Harsini ${ }^{*}$ Acknowledgements:

Hereby, the researchers appreciate the Vice Chancellor for Research and Technology of Fasa University of Medical Sciences for approval and all the help and financial support of the study as well as all the women participating as the subjects.

\section{References}

1. Reginster JY. The prevalence and burden of arthritis.Rheumatology (Oxford) 2002; 41 Supp 1: 3-6.

2. APLAR Community. The APLAR Community Oriented Program for Control of Rheumatic Disease (COPCORD), 2003: Available from: [www.ilar.org] Ref Type: Electronic Citation.

3. Mehdinasab SAH, Hadadpoor AA, Sarrafan N, Dashtbozorg A, Ebrahimi M . Prevalence and Evaluation of Risk Factors in Primary Knee Osteoarthritis. Journal of Medical science 2009; 9(2):1358. [Persian]

4. Dahaghin, Tehrani-Banihashemi SA, Gaezi ST, Jamshidi AR, Davatchi F . Squatting, sitting on the floor or cycling: are life-long daily activities risk factors for clinical knee osteoarthritis? (Tehran COPCORD study stage 111). Arthritis Rheum 2009; 61, 1337-42.

5. Thomas J Hoogeboom, Mirelle JPM Stukstette, Rob A de Bie, Jessica Cornelissen, Alfons A den Broeder and Cornelia HM van den Ende. Non pharmacological care for patients with generalized osteoarthritis: design of a randomized clinical trial. BMC musculoskeletal Disorders, 2010, 11:142. 
6. Muraki S, Akune T, Oka H, En-Yo Y, Yoshida M,Saika A, et al.Association of radiographic and symptomatic knee osteoarthritis with health-related quality of life in a population-based cohort study in Japan: the ROAD study. Med Care 2010;48(9):785-91.

7. Moghemi G. (Winter 1388). [Educational paper on osteoarthritis]. Journal of Semnan Medical Sciences University 2009; 11(2): 147-154. [Persian]

8. Pyraieh N, Talebian S, Hadian M, Aliaie Gh, Galale SH, Mazaheri h.[The balance disorders in patients with osteoarthritis of the knee]. New Rehabilitation Faculty of Rehabilitation Tehran University of Medical Sciences 2010; 4(3):19-22. [Persian]

9. Mahmoudi Aghdam S, Khademi KH, Akbarzada A, Rezaei M, Rahimi A, Sadat Naimi S. [Effect of sustained traction on physical improvements of patients with severe knee osteoarthriti]. New Journal of Rehabilitation Faculty of Rehabilitation Tehran University of Medical Sciences 2013; 7(3):25-31. [Persian]

10. Pahlavan Hosseini Hamid, [Article retraining osteoarthritis Educational paper on osteoarthritis].Journal of Medical Sciences and Health Services, Yazd martyr 2002; 10(4): 76. [Persian]

11. Nadji A, Akhlaghi M. Osteoarthiritis.1nded.Tehran: Tehran University of Medical sciences; 2012:23564.[Persian]

12. Carol Mattson Porth.Pathophysiology: concepts of altered health states. 2009; Lippincott.123-125.

13. Keshtcarran Z, Ghodsbin F, Solouki S, Razeghi M, Zare N. The Impact of Self-care education on Quality of life of Osteoarthritis patients in Rehabilitation Centers Shiraz. J Babol University of Medical Sciences 2010; 12(1): 65-6.[Persian]

14. Davatchi F, Jamshidi A-R, Banihashemi AT, Gholami J, Forouzanfar MH, Akhlaghi M, et al. WHO-ILAR COPCORD study (stage1, urban study) in Iran. The Journal of rheumatology 2008;35(7): 1384-9.

15. Dahaghin S, Tehrani-Banihashemi S, Frouzanfar M, Barghamdi M, Norollahzadeh E, Gholami J, et al. Risk factors of knee osteoarthritis, WHO-ILAR-COPCORD study. Tehran University Medical Journal 2009;66(10):721-6. [Persian]

16. Bartels EM, Lund H, Hagen KB, Dagfinrud H,Christensen R, Danneskiold-Samsøe B.Aquatic exercise for the treatment of knee and hip osteoarthritis.Cochrane Database Syst Rev 2007.17;(4):CD005523.

17. Darlene Hertling and Randolph M.Kessler. Management of Common Musculoskeletal Disorders.2008.123-124.

18. Haq SA, Davatchi F. Osteoarthritis of the knees in the COPCORD world. International Journal of Rheumatic Diseases 2011;14(2): 122-4 .[Persian]

19. Davatchi F, Jamshidi AR, Bani-Hashemi AT, Darmawan J . WHO-ILAR-COPCORD pilot study in Tehran,Iran. J Rheumatol 2006;33, 1467-8.

20. Yoshimura N, Nishioka S, Kinoshita H, Hori N, Nishioka T,Ryujin M, et al. Risk factors for knee osteoarthritis in Japanese women: heavy weight, previous joint injuries, and occupational activities. J Rheumatol 2004; 31: 157-62. 
21. Zeng QY, Zang CH, Li XF, Dong HY, Zhang AL, Lin L.Associated risk factors of knee osteoarthritis: a population survey in Taiyuan, China. Chin Med J (Engl) 2006; 119: 1522-7.

22. Michael Doherty, Edward Roddy. Changing life-styles and osteoarthritis what is the evidence? Best Practice \& Research Clinical Rheumatology2006. 20(1):. 81-97.

23. AghaAmiri M, Mohamadzade SH, SEifi B, Alavymajd H. the relationship between lifestyle and risk of osteoarthritis in elderly men and women. Women and Culture Research 2010;1(4): 620-55. [Persian]

24. Jinks C , Jordan K, Croft P. Osteoarthritis as a public health problem: the impact of developing knee pain on physical function in adults living in the community:(KNEST 3). Rheumatology 2007;46(5): 877-81

25. Didarloo A, SHojaeezade D, Mohammedian H. Promotion planning based on the model. 1nded.Tehran:Sobhan;2010:74-6. [Persian]

26. Safari M, SHojaeizade D. The principles of health education and health promotion. Tehran: Samat. 2009;1:18 .[persian]

27. Tabatabaei SVA, Taghdisi MH, Nakheei N. Effect of Educatin Intervention Based on the Theory of Planned Behavior on the Physical Activity. Babol university of medical sciences2010;12(2):62-80. [Persian]

28. Saffari M, Shojaeizadeh D. Health Education AND Promotion. 1nded.Tehran. Sobhan. 2009:79-80. (persian)

29. MazloomyMahmoodabad SS, Bajalan M, DormohammadiToosi T,Tarahi MJ, Bonyadi F. The Effect of Training on Adopting Behaviors Preventing from Knee Osteoarthritis Based on Planned Behavior Theory. Tolooebehdasht 2015;14(1):12-23.

30. Mohammadi Zeidi I, Mohammadi Zeidi B. The Effect of Stage-Matched Educational Intervention on Reduction in Musculoskeletal Disorders among Computer Users. JBUMS 2011; 14 (1) :42-49.

31. Reddy UK, Siyo RKN, Haque MAU, Basavaraja H, Acharya BLG, Divakar DD. Effectiveness of health education and behavioral intervention for tobacco de-addiction among degree students: A clinical trial. Journal of International Society of Preventive and Community Dentistry.2015;5(8):93.

32. Kwan PP, Sussman S, Valente TW. Peer Leaders and Substance Use Among High-Risk Adolescents. Substance use \& misuse. 2015; 50(3):283-91.

33. Mirzaei M, Mazloomy SS, Yassini SM, Askarshahi M, Jalilian F, Zinat Motlagh F, et al. Fathers' behavioral intention and behavior in prevention of children tendency toward addictive drugs. Iranian Journal of Health Education and Health Promotion. 2013;1(2):57-66.

34. Bashirian S, Alireza Hidarnia A, Hamid Allahverdipour H, Hajizadeh E. The Theory-Based Substance Abuse Prevention Program for Adolescents. Health Education \& Health Promotion (HEHP) (2013) ; 1(1): 3- 12.

35. Jalilian F, Allahverdipour H, Moeini B, Moghimbeigi A. Effectiveness of Anabolic Steroid Preventative Intervention among Gym Users: Applying Theory of Planned Behavior. Health promotion perspectives.2010;1(1):32-40. 
36. Mehri A, MazloomyMahmoodabad SS, Morowattysharifabad MA the impact of training on the use of motorcycle helmets staff Based on the theory of planned behavior. payesh 2010;11(1):180. [Persian].

37. Robertson M, Amick BC 3rd, DeRango K, Rooney T, Bazzani L, Harrist R, et al. The effects of an office ergonomics training and chair intervention on worker knowledge, behavior and usculoskeletal risk. Appl Ergon 2009; 40(1): 124-35.

38. Martin JJ, Oliver K, McCaughtry N. The theory of planned behavior: predicting physical activity in Mexican American children. J Sport Exerc Psychol 2007;29(2): 225-38.

39. Mousali A, Moeini B, Hazavehei SMM, Bashiriyan S, Ali Reza Soltanian A R , Kafami V. "Effectiveness of an Educational Program Based on the Theory of Planned Behavior for Improving Safe Sexual Behaviors Intention among Addicted Males: A Quasi Experimental Study." International Journal of High Risk Behaviors and Addiction Inpress (2016). : e32432 , DOI: 10.5812/ijhrba.32432.

40. Allahverdipour H, Bazargan M,Farhadinasab A, Hidarnia A, Bashirian S.Effectiveness of skill-based substance abuse intervention among male adolescents in an Islamic country case of the republic of Iran. J Drug Education 2009; 39(2): 211-22.

41. Kalte H O, Faghih M A, Taban E, Faghih A, yazdani aval M. Effectiveness of Ergonomic Training Intervention on Risk Reduction of Musculoskeletal Disorders. 3. 2015; 1 (2) :38-45.

42. Viljanen M, Malmivaara A, Uitti J, Rinne M, Palmroos P, Laippala P. Effectiveness of dynamic muscle training,relaxation training, or ordinary activity for chronic neck pain: randomised controlled trial. Bmj. 2003;327(7413):475.

43. Thomas KS1, Muir KR, Doherty M, Jones AC, O'Reilly SC, Bassey EJ. Home based exercise programme for knee pain and knee osteoarthritis: randomised controlled trial. BMJ. 2002 Oct 5;325(7367):752.

44. Albaladejo C, Kovacs FM, Royuela A, Del Pino R, Zamora J. The efficacy of a short education program and a short physiotherapy program for treating low back pain in primary care: a cluster randomized trial. Spine 2010;35:483e96.

45. Coleman S, Briffa NK, Carroll G, Inderjeeth C, Cook N, McQuade J. A randomized controlled trial of a self-management education program for osteoarthritis of the knee delivered by health care professionals. Arthritis Res Ther 2012;14.

46. French SD, McKenzie JE, O'Connor DA, Grimshaw JM, Mortimer D, Francis JJ, et al.Evaluation of a theory-informed implementation intervention for the management of acute low back pain in general medical practice: the IMPLEMENT cluster randomised trial. PLoS One 2013;8(6):e65471.

47. Kroon F, Burg Lvd, Buchbinder R, Osborne R, Johnson R, Pitt V. Self-management education programmes for osteoarthritis (review) Cochrane Database Syst Rev 2014;1.

48. Tavafian SS, Jamshidi AR, Montazeri A. A randomized study of back school in women with chronic low back pain: quality of life at three, six, and twelve months follow-up. Spine 2008;33:1617e21.

49. Erfanian zorofi F, Mahtab Moazzami M, Mohammadi M. The Effect of Resistance Training on Static Balance and Pain in Elderly Women with Varus Knee and Osteoarthritis by Using Elastic Band. JPSR 
$2016 ; 5(2): 14-24$.

50. Allegrante JP, Kovar PA, MacKenzie CR, Peterson MG, Gutin B. A walking education program for patients with osteoarthritis of the knee: theory and intervention strategies. Health Educ Q. 1993 Spring;20(1):63-81.

\section{Tables}

Tables 1 and 2 are not available with this version. 